\title{
PELATIHAN DAN PENDAMPINGAN GURU OLAHRAGA SEKOLAH DASAR MENGHADAPI O2SN DI KOTA SINGKAWANG
}

\author{
Stephani Yane ${ }^{1}$, Zainal Arifin', Heri Rustanto ${ }^{3}$ \\ ${ }^{123}$ Program Studi Penjaskesrek, Fakultas Pendidikan Olahraga dan Kesehatan \\ IKIP PGRI Pontianak, Jalan Ampera No. 88 \\ 1e_mail: Stephaniyane@Gmail.com
}

\begin{abstract}
Abstrak
Permasalahan yang dihadapi Oleh Dinas Pemuda Olahraga Kota Singkawang adalah menurunnya prestasi atlit pada tingkat pelajar pada gelaran O2SN, Kota Singkawang meraih tiga mendali emas pada tahun 2016 dan sampai tahun 2017 peringkat semakin menurun meraih 1 mendali perunggu sampai pada tahun 2018. Permasalahan mendasar yang menjadi faktor kegagalan tersebut adalah dikarenakan kurang optimalnya penelusuran bakat yang dilakukan oleh sekolah-sekolah pada tingkat dasar, dimana penelusuran hanya dilakukan dengan menggunakan infentarisir hasil lomba yang dipertandingkan pada tingkat sekolah saja. Program Pengabdian Kepada Masyarakat ini bertujuan untuk meningkatkan sistem serta mekanisme pencarian bakat yang dilakukan secara terprogram melalui kegiatan pelatihan dan pendampingan kepada guru-guru olahraga pada tingkat Sekolah Dasar. Program-program yang telah dilaksanakan diantaranya adalah; (1) Pemberian materi tentang identifikasi bakat olahraga di sekolah; (2) Pemberian materi tentang Modifikasi Alat Olahraga; (3) Pemberian materi tentang penanganan cidera olahraga; (4) Pelatihan tes identifikasi bakat olahraga; (5) Pelatihan pembuatan alat modifikasi untuk olaharaga; (6) Pelatihan fisik untuk anak-anak. Metode yang dipakai dalam pencapaian tujuan tersebut adalah penyelenggaraan inservice berupa pelatihan dan pendampingan.
\end{abstract}

Kata Kunci: Penelusuran bakat olahraga di sekolah, Identifikasi Bakat Olahraga di Sekolah.

\begin{abstract}
The problem faced by the Singkawang City Education, Youth, and Sport Office is the decline in athlete achievement at the O2SN level, the City of Singkawang won three gold medals in 2016 and until 2017 the ranking has declined to reach 1 bronze medal until 2018. Fundamental issues which are a factor The failure is due to the lack of optimal talent search conducted by schools at the primary level, where the search is only done by using an inventory of the results of a competition that is competed at the school level only. This Community Service Program aims to improve the system and mechanism for talent search that is programmed through training and assistance to sports teachers at the elementary school level. The programs that have been implemented include; (1) Providing material about identifying sports talent in schools; (2) Providing material about Sports Equipment Modification; (3) Providing material on handling sports injuries; (4) Training for sports talent identification tests; (5) Training in making modification tools for sports; (6) Physical training for children. The method used in achieving these objectives is the implementation of inservice in the form of training and assistance.
\end{abstract}

Keywords: Search for sports talent at school, Identify Sports Talent at School. 


\section{PENDAHULUAN}

Olahraga selain untuk kesehatan juga merupakan salah satu wahana untuk mengharumkan nama bangsa, dari olahraga banyak hal yang harus diperhatikan baik untuk peningkatan prestasi maupun untuk kebugaran fisik. Prestasi yang sukses dihasilkan dari atlet yang memiliki bakat pada cabang olahraga tertentu yang diikuti. Sistem pembinaan prestasi olahraga yang diikuti oleh sistem pembinaan olahraga di Indonesia yaitu mengerucut keatas yang paling bawah pembinaan usia dini diatasnya spesialisai dan lanjut ke prestasi. Jadi untuk mencapai jenjang prestasi tinggi diperlukan sistem pembibitan yang baik. Tanpa pembibitan yang tersistem dengan baik maka tahap pencapaian prestasi tidak akan tercapai dengan baik. Kota Singkawang pada saat ini masih kesulitan dalam meningkatkan prestasi atlet-atlet mereka pada beberapa cabang olahraga. Permasalahan yang dihadapi oleh Dinas Pemuda Olahraga Kota Singkawang adalah menurunnya prestasi atlet pada tingkat pelajar pada gelaran O2SN, Kota Singkawang meraih tiga mendali emas pada tahun 2016 dan sampai tahun 2017 peringkat semakin menurun meraih 1 mendali perunggu sampai pada tahun 2018. Berdasarkan hasil wawancara dengan Kepala Dinas Pemuda dan Olahraga Kota Singkawang, beliau mengatakan bahwa beberapa factor penting dalam meningkatkan prestasi atlet sepertinya masih jauh dari yang diharapkan. Hal tersebut dapat terlihat dari fasilitas sarana dan prasarana yang tidak memadai, factor pelatih/guru penjas Sekolah Dasar juga sangat berpengaruh saat ini mereka sendiri pun mengalami keterbatasan dalam mengidentifikasi bakat dalam menentukan cabang olahraga apa saja yang cocok untuk atlet dari sekolah mereka. Sehingga banyak atlet yang mereka hasilkan sebagian besar adalah atlet yang tidak berbakat dicabang olahraga yang diikuti, serta postur tubuh yang tidak mendukung di semua karakteristik dari masing-masing cabang olahraga. Faktor berikutnya adalah pembinaan yang tidak berjalan secara konsisten berdasarkan kategori usia, dimana factor pembinaan untuk kategori usia muda masih berharap dari seleksi yang dilakukan oleh pihak sekolah yang diikut sertakan pada O2SN (Olimpiade/Olahraga Sekolah Nasional) tingkat sekolah. 
Untuk mendapatkan calon atlet yang kelak diharapkan dapat meraih prestasi, diperlukan upaya dengan beberapa tahapan. Bompa menyatakan ada beberapa tahapan yang harus dikuti untuk mempersiapkan atlet. Adapun tahapan yang dimaksud adalah: (1) Mencari calon atlet berbakat; (2) Memilih calon atlet pada usia muda; (3) Memonitor calon atlet tersebut secara terus-menerus dan teratur; (4) Membantu calon atlet agar dapat meraih prestasi puncak. Selama ini hasil observasi menunjukkan bahwa eksistensi atlet elit selalu berkait erat dengan kerja dan waktu yang diinvestasikan para pelatih kepada calon atlet yang memiliki kemampuan alami superior. Dalam pernyataan tersebut tersirat suatu peringatan ataupun arahan agar supaya potensi, waktu dan energi yang dimiliki pelatih tidak terbuang tanpa arti dalam proses kepelatihannya, demikian juga dengan diperolehnya hasil berlatih yang jauh dari optimal, maka perlu dilakukan pemilihan calon atlet yang mempunyai kemungkinan paling besar untuk mengembangkan potensinya. Dengan demikian, dapatlah ditarik konklusi bahwa tujuan utama melakukan identifikasi calon atlet adalah untuk mengidentifikasi dan memilih calon atlet yang mempunyai kemampuan terbaik sesuai dengan cabang olahraga yang dipilih.

Bompa (1990) menyatakan di negara barat identifikasi calon atlet bukanlah merupakan suatu konsep baru dalam bidang olahraga, meskipun kegiatan identifikasi calon atlet ini belum banyak dikerjakan secara formal. Sebagai ilustrasi dapat dicermati keadaan berikut: pada akhir tahun 1960-an dan awal tahun 1970-an, sebagian besar negara Eropah Timur telah menetapkan metode khusus untuk melakukan identifikasi calon atlet potensial. Prosedur pemilihan calon atlet ditemukan dan diarahkan oleh para ilmuwan olahraga, selanjutnya para ilmuwan memberikan rekomendasi beberapa calon atlet berpotensi dalam cabang olahraga tertentu kepada para pelatih.

Seleksi pada tingkat sekolah tersebut sebenarnya juga bukan tanpa masalah beberapa permasalahan muncul seperti tidak adanya regulasi yang jelas terkait seleksi bibit-bibit muda, guru lebih melihat kepada bakat alami yang dimiliki oleh siswa dengan mengenyampingkan penguasaan teknik dasar, dan waktu seleksi dilakukan pada jangka pendek. Selain dari pada itu Kepala Dinas Pemuda dan 
Olahraga Kota Singkawang mengatakan bahwa beberapa faktor lain yang tak kalah pentingnya dalam peningkatan prestasi atlet adalah dilakukannya penelusuran bakat yang dilakukan oleh sekolah-sekolah pada tingkat dasar, dimana sampai saat ini penelusuran hanya dilakukan dengan menggunakan infentarisir hasil lomba yang dipertandingkan pada tingkat sekolah saja, penelusuran bakat atlet tidak dilakukan secara sistematis terprogram dengan melibatkan para ahli di bidang olahraga.

Berdasarkan observasi yang dilakukan, ketua KKG Penjas Kota Singkawang mengatakan bahwa masih banyak terdapat kelemahan-kelemahan dalam melakukan seleksi bibit-bibit muda potensial pada beberapa cabang olahraga pada usia dini di sekolah, selain keterbatasan sarana dan prasarana, keterampilan guru dalam mengidentifikasi beberapa faktor yang mempengaruhi perkembangan bakat siswa tergolong masih rendah dan tidak memiliki instrumen yang memadai. Beberapa faktor yang harus diperhatikan tersebut adalah factor fisiologi, factor teknik, factor psikologis, factor teknis lainnya seperti strategi dan taktik yang digunakan serta yang tak kalah pentingnya adalah perkembangan fisik dari atlet itu sendiri karena sekolah tidak memiliki biaya untuk asupan gizi mereka sehingga pihak sekolah hanya dapat memberikan rekomendasi kepada atlet untuk tidak mengkonsumsi makanan, minuman yang mengandung zat-zat berbahaya bagi perkembangan fisik atlet. Kedepannya pihak KKG Penjas berharap ada kerjasama dan tanggungjawab bersama antara Dinas Pemuda dan Olahraga dengan pihak KKG dalam menjaga potensi bibit-bibit muda potensial mulai dari permasalahan yakni kegiatan-kegiatan yang melibatkan anak-anak usia dini untuk berolahraga agar diperoleh bibit-bibit olahragawan yang handal; kemudian melakukan pembibitan; yakni melakukan pemilihan atlet-atlet berbakat dengan cara-cara yang ilmiah dan yang terakhir adalah prestasi; seperti yang telah dibicarakan sebelumnya termasuk pada kegiatan pembinaan atlet. 


\section{Permasalahan Mitra}

Permasalahan yang dihadapi sekolah mitra dalam melakukan penelusuran bakat terhadap atlet potensial pada usia dini dapat dinyatakan sebagai berikut:

a) Tidak dilakukannya identifikasi bakat olahraga di sekolah secara terprogram.

b) Tidak memiliki keterampilan dalam melakukan pemanduan bakat berdasarkan tes fisik.

c) Tidak memiliki keterampilan dalam modifikasi alat olahraga serta penanganan cidera olahraga.

\section{METODE}

Metode yang dipakai dalam pencapaian tujuan Program Kemitraan ini adalah penyelenggaraan inservice berupa pelatihan dan pendampingan. Pelatihan dan pendampingan yang diterapkan adalah metode pengenalan bakat (Talent Identification) yang diintegrasi dengan pola latihan dengan menggunakan teknologi alat latihan termodifikasi dengan mengungkap permasalahan yang muncul dikalangan para guru, kemudian dilakukan diskusi pengusul bersama mitra untuk merumuskan akar masalah prioritas yang disepakati, serta menentukan solusi yang tepat (Milo Koretsky, at.al. 2011). Bahwa tidak efektifnya serta rendahnya prestasi olahraga di Kota Singkawang adalah salah satu faktornya dikarenakan lemahnya pengenalan bakat olahraga yang dimiliki siswa di sekolah oleh guruguru olahraga, kelemahan tersebut teridentifikasi karena guru-guru olahraga tidak memiliki keterampilan yang memadai untuk menyusun instrumen-instrumen yang terkait pada identifikasi bakat serta pembinaan atlet usia dini di sekolah.

Pendekatan pertama dilakukan dengan cara menyusun tes baterei, sedangkan pendekatan kedua dilakukan yang telah dikembangkan para ahli. Salah satu tes baku terkenal adalah tes identifikasi bakat dari Australian Sports Commision. Tes identifikasi bakat tersebut pada tahun 1998 telah diadopsi dan diadaptasikan oleh Kantor Negara Pemuda dan olahraga, yang dapat mengukur kemampuan / potensi anak usia dini, dengan menggunakan 10 macam item, sebagai berikut: (1) tinggi badan, (2) tinggi (porsi) duduk, (3) berat badan, (4) lebar rentang tangan, (5) kemampuan melempar dan menangkap bola tenis, (6) kemampuan berapa jauh 
melempar bola basket, (7) tinggi loncat vertical, (8) kelincahan lari, (9) lari cepat jarak 40 meter, (10) "multistage fitness test", untuk memprediksi kapasitas VO2 Max.

Tabel 1. Faktor, Bentuk, Dan Butir Tes

\begin{tabular}{|c|c|c|c|}
\hline NO & FAKTOR & BENTUK TES & PARAMETER \\
\hline 1 & $\begin{array}{l}\text { BENTUK DAN UKURAN } \\
\text { TUBUH }\end{array}$ & $\begin{array}{l}\text { 1. TINGGI BADAN } \\
\text { 2. BERAT BADAN } \\
\text { 3. TINGGI DUDUK } \\
\text { 4. RENTANG } \\
\text { LENGAN }\end{array}$ & $\begin{array}{l}\text { 1. CENTIMETER } \\
\text { 2. KILOGRAM } \\
\text { 3. CENTIMETER } \\
\text { 4. CENTIMETER }\end{array}$ \\
\hline 2 & $\begin{array}{l}\text { 2. KEMAMPUAN } \\
\text { JASMANI TERDIRI } \\
\text { DARI: } \\
\text { KOORDINASI TANGAN- } \\
\text { MATA } \\
\text { KEKUATAN BADAN } \\
\text { BAGIAN ATAS } \\
\text { POWER (DAYA LEDAK) } \\
\text { KELINCAHAN } \\
\text { KECEPATAN } \\
\text { KAPASITAS AEROBIK } \\
\end{array}$ & $\begin{array}{l}\text { LEMPAR TANGKAP } \\
\text { LEMP. B. BASKET } \\
\text { LOMPAT TEGAK } \\
\text { LARI BOLAKBALIK } \\
\text { LARI } 40 \text { METER } \\
\text { LARI MULTI } \\
\text { TAHAP }\end{array}$ & $\begin{array}{l}\text { 5. FREKUENSI } \\
\text { 6. METER } \\
\text { 7. CENTIMETER } \\
\text { 8. DETIK } \\
\text { 9. DETIK } \\
\text { 10. TINGKAT }\end{array}$ \\
\hline
\end{tabular}

Modifikasi secara umum diartikan sebagai usaha untuk mengubah atau menyesuaikan. Namun secara khusus modifikasi adalah suatu upaya yang dilakukan untuk menciptakan dan menampilkan sesuatu hal yang baru, unik, dan menarik. Modifikasi disisni mengacu kepada sebuah penciptaan, penyesuaian dan menampilkan suatu alat/sarana dan prasarana yang baru, unik, dan menarik terhadap suatu proses belajar mengajar pendidikan jasmani. Pelaksanaan modifikasi sangat diperlukan bagi setiap guru pendidikan jasmani sebagai salah satu alternative atau solusi dalam mengatasi permasalahan yang terjadi dalam proses belajar mengajar pendidikan jasmani, modifikasi merupakan implementasi yang sangat berintegrasi dengan aspek pendidikan lainnya.

Arti modifikasi secara umuma dalah mengubah atau menyesuaikan. Modifikasi adalah cara merubah bentuk barang dari yang kurang menarik menjadi lebih menarik tanpa menghilangkan fungsi aslinya, serta menampilkan bentuk yang lebih bagus dari aslinya. Mengenai pengertian modifikasi, Bahagia 
(2010:13), mengemukakan bahwa: modifikasi dapat diartikan sebagai upaya melakukan perubahan dengan penyesuaian-penyesuaian baik dalam segi fisik material (fasilitas dan perlengkapan) maupun dalam tujuan dan cara (metoda, gaya, pendekatan, aturan serta penilaian).

Apabila modifikasi dikaitkan dengan pembelajaran pendidikan jasmani mempunyai makna yang cukup luas, baik modifikasi dalam bentuk benda atau kecakapan yang dimiliki peserta didik. Pelaksanaan modifikasi sangat diperlukan bagi setiap guru sebagai salah satu alternative atau solusi mengatasi permasalahan yang terjadi dalam proses pembelajaran pendidikan jasmani.

Berdasarkan kajian empiris yang telah dipaparkan di atas, maka pendekatan solusi yang digunakan untuk memecahkan dua permasalahan pokok yang dihadapi sekolah mitra adalah penyelenggaraan inservice berupa pelatihan dan pendampingan. Pendampingan dilakukan terkait dengan meningkatkan keterampilan guru dalam mengidentifikasi bakat olahraga siswa secara alamiah dan ilmiah, sedangkan dua target pelatihan adalah pelatihan mengembangkan keterampilan dan kreativitas guru olahraga dalam produksi/merancang alat latihan termodifikasi serta instrumen-instrumen identifikasi bakat dan latihan. Dalam pelaksanaannya metode pendekatan yang ditawarkan adalah partisipasi, dalam artian tim pengusul dan mitra secara proaktif terlibat dalam setiap kegiatan.

IKIP PGRI Pontianak sebagai lembaga pendidikan tinggi senantiasa melaksanakan tri darma perguruan tinggi yakni pengajaran, pendidikan dan pengabdian kepada masyarakat. Melalui koordinasi Lembaga Penelitian dan Pengabdian Kepada Masyarakat (LPPM IKIP PGRI Pontianak), kegiatan pengabdian dilakukan secara berkala dalam setiap tahunnya baik dengan dana lembaga maupun dengan dana DIKTI. Misalnya saja dalam setiap tahunnya LPPM IKIP PGRI Pontianak melakukan pengabdian kepada masyarakat khususnya diwilayah Kalimantan Barat. Bentuk pengabdian yang dilakukan dalam bentuk penyuluhan, pelatihan, penerapan dan penyebar luasan IPTEK yang tepat guna, berdaya guna dan spesifik lokal yang menyangkut semua bidang ilmu yang ada pada instansi tersebut. Hasil dari kegiatannya selalu dipublikasikan dalam bentuk artikel ilmiah nasional. 
ISSN 2598-6147 (Cetak)

ISSN 2598-6155 (Online)

\section{HASIL DAN PEMBAHASAN}

Berdasarkan pada program kerja dan target tim PKM hingga saat ini pelaksanaan program telah mencapai $100 \%$ dari total keseluruhan rancangan program. Ketercapaian tersebut dapat dilihat pada tabel berikut.

Tabel 1. Ketercapaian Program PKM

\begin{tabular}{|c|l|c|c|}
\hline \multirow{2}{*}{ No } & & \multicolumn{1}{|c|}{ Pelaksanaan } \\
\cline { 3 - 4 } & & \multicolumn{1}{|c|}{ Program Kegiatan } & Tidak \\
Terlaksana & $(\%)$ & $\begin{array}{c}\text { Terlaksana } \\
(\%)\end{array}$ \\
\hline 1 & Penyampaian materi identifikasi bakat olahraga & $100 \%$ & - \\
\hline 2 & Penyampaian materi latihan fisik untuk anak- & $100 \%$ & - \\
\hline 3 & Penyampaian materi penanganan cidera olahraga & $100 \%$ & - \\
\hline 4 & Pendampingan pelatihan tes identifikasi bakat & $100 \%$ & - \\
\hline 5 & Pendampingan perancangan alat olahraga & $100 \%$ & - \\
\hline 6 & Pendampingan pelatihan fisik untuk siswa & $100 \%$ & \\
\hline
\end{tabular}

Lokasi kegiatan dilaksanakan di dua tempat, hari pertama tanggal 1 Agustus 2019 pelaksanaan dilakukan di Gedung PMI jalan Dr. Sutomo Kelurahan Pasiran Kecamatan Singkawang Barat. Hari kedua tanggal 2 Agustus 2019 kegiatan dilaksanakan di Lapangan Tarakan Jalan RA. Kartini Kelurahan Sekip Lama. 
ISSN 2598-6147 (Cetak)

ISSN 2598-6155 (Online)

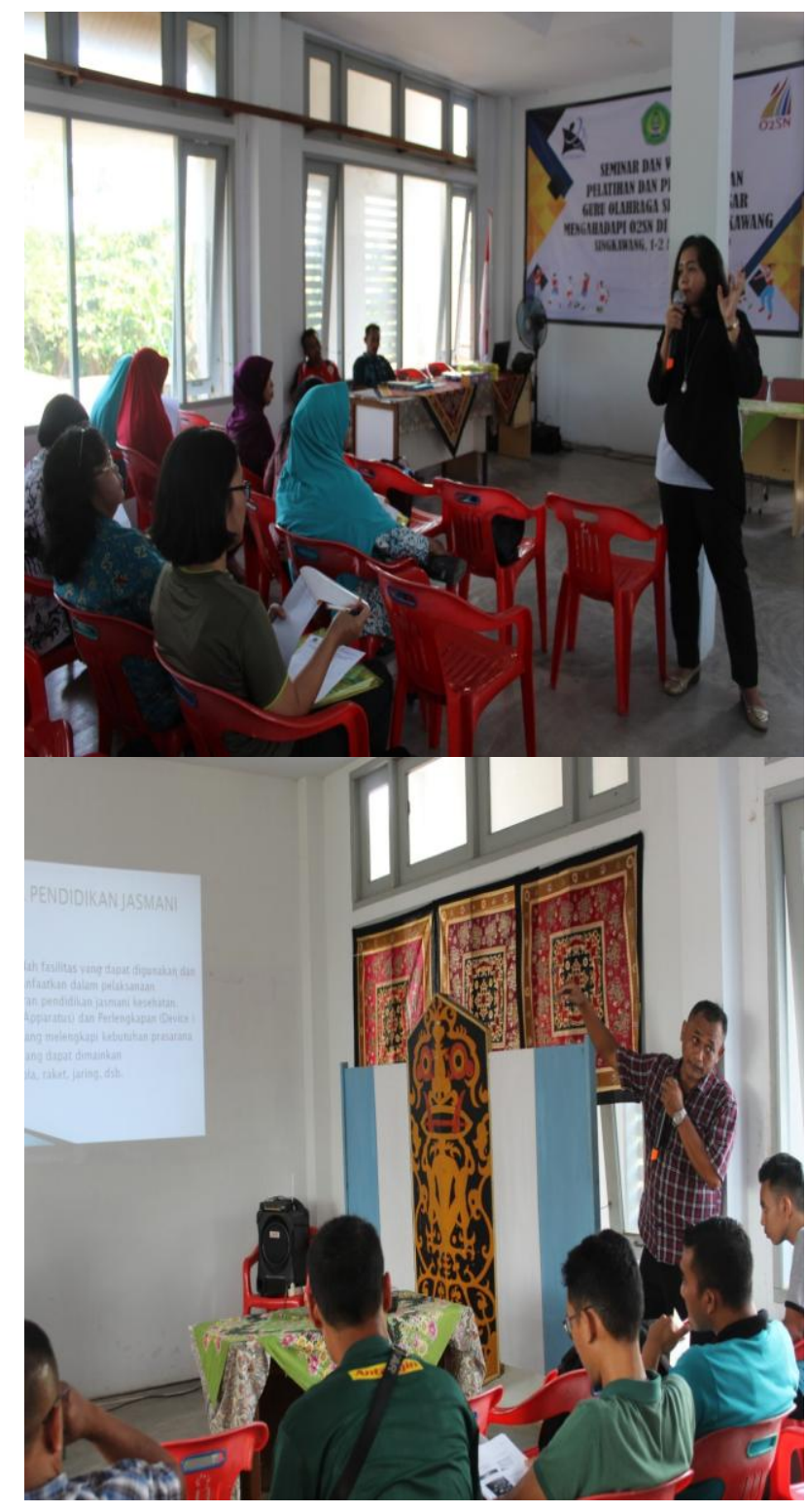

Gambar 2.1. Pelaksanaan kegiatan hari pertama di Gedung PMI 


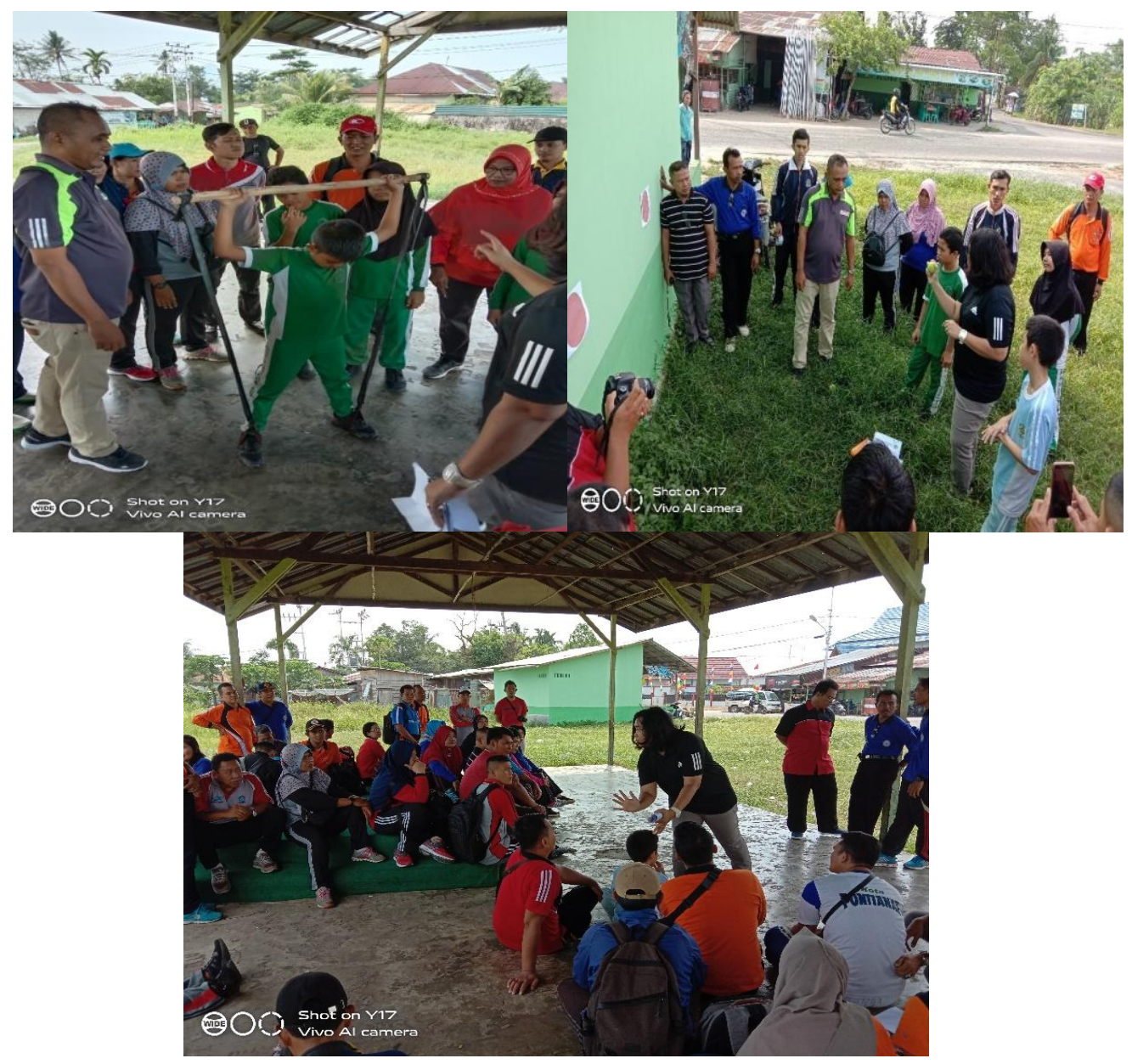

Gambar 3.1. Pembimbingan dan pendampingan yang dilakukan oleh pelaksana PKM

\section{Luaran yang dihasilkan}

Setelah dilaksanakannya kegiatan Pengabdian Kepada Masyarakat selama dua hari, luaran yang dihasilkan sejauh ini dipetakan seperti tabel 2 di bawah ini.

Tabel 2. Luaran Kegiatan Program Kemitraan Masyarakat (PKM)

\begin{tabular}{|c|c|c|c|}
\hline No & Jenis Luaran & Target Luaran & Spesifikasi \\
\hline 1 & $\begin{array}{l}\text { Instrumen berupa } \\
\text { lembar } \\
\text { pengamatan } \\
\text { identifikasi bakat } \\
\text { olahraga serta } \\
\text { instrumen berupa }\end{array}$ & $\begin{array}{l}\text { Setiap mitra (guru } \\
\text { olahraga) mampu } \\
\text { menyusun instrumen } \\
\text { identifikasi bakat } \\
\text { olahraga serta lembar } \\
\text { penilaian latihan. }\end{array}$ & $\begin{array}{l}\text { a. Instrumen yang disusun } \\
\text { sudah disesuaikan } \\
\text { dengan referensi yang } \\
\text { relevan } \\
\text { pembinaan atlet usia } \\
\text { dini. }\end{array}$ \\
\hline
\end{tabular}




\begin{tabular}{|c|c|c|c|}
\hline & $\begin{array}{c}\text { lembar penilaian } \\
\text { latihan siswa. }\end{array}$ & & \\
\hline 2 & $\begin{array}{l}\text { Program pelatihan } \\
\text { fisik yang } \\
\text { dikategorikan pada } \\
\text { tingkatan usia } \\
\text { siswa. }\end{array}$ & $\begin{array}{l}\text { Setiap mitra (guru } \\
\text { olahraga) mampu } \\
\text { menyusun program } \\
\text { latihan fisik yang } \\
\text { dikategorikan } \\
\text { berdasarkan tingkatan } \\
\text { usia siswa. }\end{array}$ & $\begin{array}{l}\text { a. Program yang disusun } \\
\text { telah disesuaikan dengan } \\
\text { standarisasi. }\end{array}$ \\
\hline 3 & $\begin{array}{l}\text { Alat latihan } \\
\text { (modifikasi) untuk } \\
\text { melakukan latihan } \\
\text { fisik. }\end{array}$ & $\begin{array}{c}\text { Setiap guru olahraga } \\
\text { dapat membuat alat-alat } \\
\text { modifikasi yang dapat } \\
\text { digunakan oleh siswa } \\
\text { latihan fisik di sekolah. }\end{array}$ & $\begin{array}{l}\text { b. Alat-alat latihan bersifat } \\
\text { portable dan mudah } \\
\text { digunakan. } \\
\text { c. Menggunakan bahan- } \\
\text { bahan yang mudah } \\
\text { didapat. } \\
\text { d. Alat-alat yang dibuat } \\
\text { sudah sesuai dengan } \\
\text { prosedur kepelatihan } \\
\text { olahraga. }\end{array}$ \\
\hline 4 & Artikel Ilmiah & $\begin{array}{c}\text { Artikel dipublikasikan } \\
\text { pada jurnal Pengabdian } \\
\text { Kepada Masyarakat. }\end{array}$ & Jurnal Nasional Ber-ISSN. \\
\hline 5 & Publikasi ilmiah & $\begin{array}{l}\text { Kegiatan dipublikasikan } \\
\text { di media massa. }\end{array}$ & Publikasi pada media massa. \\
\hline
\end{tabular}

\section{SIMPULAN}

Setelah dilaksanakannya kegiatan PKM selama dua hari, beberapa hal yang dicapai dari pelatihan dan pendampingan adalah :

1. Sebanyak $70 \%$ guru olahraga memiliki kemampuan dan keterampilan untuk mengidentifikasi bakat-bakat olahraga yang dimiliki oleh siswa di sekolah.

2. Sebanyak $80 \%$ guru olahraga memiliki kemampuan dalam menyusun instrument yang 
tepat yang dapat digunakan untuk mengidentifikasi bakat olahraga yang dimiliki oleh siswa.

3. Sebanyak $80 \%$ Guru olahraga memiliki kemampuan dalam menyusun pola latihan fisik yang baik sesuai dengan kategori usia siswa.

4. Sebanyak 50\% Guru olahraga memiliki keterampilan dalam menangani permasalahan cidera yang dialami oleh siswa.

\section{UCAPAN TERIMA KASIH}

Ucapan terima kasih kami sampaikan ke beberapa pihak yang berperan dalam kegiatan pengabdian kepada masyarakat antara lain:

1. Kemenristekdikti.

2. Dinas Pendidikan dan Kebudayaan Kota Singkawang.

3. IKIP PGRI Pontianak.

4. Lembaga Penelitian dan Pengabdian Pada Masyarakat IKIP PGRI Pontianak.

5. Kelompok Kerja Guru (KKG) Penjaskes Kota Singkawang.

\section{DAFTAR PUSTAKA}

Bompa Tudor O. (1990) Theory And Methodology of Training: The Key to Athletic Performance. Dubuque. Iowa: Kendall/Hunt Publishing Company.

Hastad D. N. dan Lacy A. C. (1989) Measurement And Evaluation: In Contemporary Physical Education. Scottsdale, Arizona: Gorsuch Scarisbrick, Publishers.

Hoare D. ( 1995) Talent Identification For Team Sports (Materi disajikan dalam Lokakarya Nasional Olahraga dan Kepelatihan diselenggarakan oleh kantor Menpora).

Kantor Menteri Negara Pemuda dan Olahraga (1998) Pedoman Pemanduan Bakat Olahraga. Jakarta: Kantor MENPORA.

Safrit J. M. (1986) Introduction To Measurement In Physical Education And Exercise Science. Lagos, St. Louis: Times Mirror/MosbyCollege Publishing. Arnot, R. B. dan Gaines C. L. Sports Talent. 